La influencia persuasiva de los estímulos eróticos en la publicidad sobre las tendencias de consumo de los jóvenes 


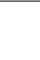




\section{La influencia persuasiva de los estímulos eróticos en la publicidad sobre las tendencias de consumo de los jóvenes (Parte 1)}

Fecha de recepción: 29 de marzo de 2011

Fecha de aceptación: 23 de junio de 2011

Hugo Mastrodoménico Brid

Universidad Jorge Tadeo Lozano

hugo.mastrodomenico@utadeo.edu.co

Psicólogo de la Universidad Nacional de

Colombia.Especialista en Comunicación/

Educación de la Universidad Central. Magíster en

Mercadeo Agroindustrial de la Universidad Jorge

Tadeo Lozano.

\section{Resumen}

Con el propósito de obtener evidencia empírica sobre el posible impacto persuasivo de ciertas técnicas empleadas y debatidas en el mundo de la publicidad, se compararon las respuestas de 430 estudiantes universitarios de cinco instituciones quienes fueron expuestos, en un diseño experimental intragrupos, ante pares de piezas publicitarias similares excepto por la presencia o ausencia de estímulos eróticos, con contenido simbólico inconsciente de tipo fálico, vaginal, coital, oral y eyaculatorio, y presentando o no estímulos subliminales. Se encontró que, en términos generales, la presencia de los estímulos eróticos y de los contenidos simbólicos inconscientes sí aumenta la disposición de adquirir los productos anunciados y la preferencia por el anuncio, aunque también produce un mayor rechazo moralista. Lo contrario ocurrió cuando los contenidos eróticos eran extremos y reconocidos como tales y, sin ser reconocidos, con los estímulos subliminales. Estos resultados confirman los argumentos de algunos críticos de la actividad publicitaria que denuncian estas prácticas, pero también apoyan la justificación de algunos publicistas para el empleo de estas técnicas por su efectividad.

De otra parte, los resultados relativizan algunos hallazgos obtenidos en otros estudios llevados

\section{Abstract}

In order to obtain empirical evidence about the possible impact of certain persuasive techniques used and discussed in the advertising world, we compared the responses of 430 college students from five institutions who were exposed, in an experimental design among groups, to a couple of similar advertisements, except for the presence or absence of erotic stimuli, with unconscious phallic, vaginal, coital, oral, and ejaculatory symbolic content, and presenting or not subliminal stimuli. In general terms, we found that the presence of erotic stimuli and unconscious symbolic content does increase the willingness to purchase the products advertised and the preference for the ad, but also produces a higher moral rejection. The opposite occurred when the erotic content was extreme and recognized as such, and, without being recognized, with subliminal stimuli. These results confirm the arguments of some advertising critics who not only report these practices, but also support the justification that some advertisers have for the use of these techniques for their effectiveness.

Furthermore, the results relativize some findings from other studies conducted in other cultures and support some theories of the Freudian psychoanalytic theory, especially in the field of possible unconscious interpretation of symbols. Similarly, 
a cabo en otros contextos culturales y le brindan soporte a algunos postulados de la teoría psicoanalítica freudiana especialmente en el campo de la posible interpretación inconsciente de símbolos. Igualmente, los resultados aportan nuevas luces al debate sobre los estímulos subliminales al evidenciar nuevamente su captación, pero también la existencia de defensas inconscientes ante ellos.

\section{Palabras clave}

Publicidad, estímulos eróticos, tendencias de consumo, jóvenes. the results provide new insights to the debate on subliminal stimuli to demonstrate again how they are perceived, but also the existence of unconscious defenses against them.

\section{Keywords}

Publicity, Erotic Stimuli, Consumption Tendencies, Youth. 


\section{Introducción}

Antes de que existiera la palabra publicidad ya eran comunes las polémicas públicas acerca de los usos y los abusos de esta actividad. Cuando en los periódicos comenzaron a aparecer los anuncios pagados por los comerciantes para promocionar sus productos $\mathrm{y}$ servicios, algunas personas plantearon dudas acerca de lo que es lícito hacer y cuáles son los límites éticos y legales de una gestión que siempre tuvo una clara intención de ejercer influencia sobre las actitudes y el comportamiento de compra de las personas (Mucchielli, 1977).

Uno de los temas que más discusiones ha generado, sobre todo entre las personas corrientes, es el de la utilización de los contenidos eróticos en las piezas publicitarias. Con un enfoque que algunos han dado en llamar "rechazo moralista" (Balle, 1991), se han levantado voces de protesta por el efecto pernicioso que para la sociedad, especialmente para los niños, puede tener la exaltación del deseo sexual y la permanente presenta-ción de un valor, que aunque es natural a la condición humana y evidente en la vida cotidiana, muchas veces ha sido considerado como nocivo en la mayoría de los sistemas morales conocidos: el atractivo sexual como criterio para considerar exitosa e importante a una persona.

En la década de los setenta, algunos de los críticos más acérrimos de la actividad publicitaria como Vance Packard y Wilson Bryan Key lograron gran notoriedad por sus denuncias sobre los manejos poco éticos que, según ellos, hacen los publicistas cuando apelan a los más bajos instintos y recurren a formas ocultas, y a veces ilegales, para influir en el comportamiento de las personas. Los escritos de estos autores están llenos de historias $\mathrm{y}$ anécdotas de productos que no lograban venderse mediante las técnicas tradicionales pero una vez se emplearon las prácticas denunciadas, sus ventas se multiplicaron.

No obstante, algunas investigaciones han arrojado resultados que hacen pensar que el empleo de estímulos eróticos en la publicidad no sólo podría fracasar en el intento de lograr los objetivos comerciales que se proponen los anunciantes, sino producir efectos contraproducentes para el producto anunciado. Un estudio realizado en Estados Unidos encontró que, si bien los estímulos eróticos garantizan la atención de la audiencia, no lo hacen con aquella a la que va dirigida. Se encontró que los anuncios en los que aparecen mujeres en poses atrevidas o cargadas de erotismo son más vistos por las mujeres que por los hombres $\mathrm{y}$ que los anuncios en los que los modelos masculinos intentan atraer la atención de las mujeres son más efectivos con la audiencia masculina. También se encontró que los estímulos eróticos no mejoran necesariamente la recordación de una marca, pues aunque las personas recuerdan el estímulo erótico, no logran retener el nombre del producto anunciado (Schultz, 1979, citado por Garrison \& Loredo, 2002).

En nuestro medio, sin embargo, los publicistas continúan empleando en grandes cantidades los estímulos eróticos, hecho que nos estaria indicando que la táctica sigue siendo eficaz, pues sólo así se explicaría la continuidad de un procedimiento que implica enormes inversiones monetarias y que de no producir los efectos esperados habria dejado de utilizarse hace mucho tiempo.

Dada la contradicción entre la práctica publicitaria y algunos estudios, en el campo de las investigaciones sobre el comportamiento del consumidor se reconoce expresamente la necesidad de efectuar más investigaciones en esta área del conocimiento (Loudon \& Della Bitta, 1995).

Un asunto todavía más polémico se refiere a la utilización del llamado "simbolismo inconscien--te", una aplicación derivada del psicoanálisis freudiano que consiste en utilizar los estímulos eróticos (fálicos, vaginales, coitales, etc.) pero de una manera que no resulte evidente para el público porque se trataría de imágenes o palabras con contenido sexual escondido en símbolos que serian interpretados inconscientemente. Los mensajes irian dirigidos al ello pero eludiendo las defensas y la crítica del superyó por cuanto la persona no se da cuenta de cuál es la táctica empleada por el anunciante. Una estrategia fundada en este tipo de consideraciones, independientemente de su ocurrencia en el campo psíquico de las personas y de su posible eficacia como medio para aumentar las ventas, estaria claramente violando los derechos humanos y no podría ser considerada persuasiva sino coercitiva, pero, con todo, su utilización en algunos anuncios es un hecho (Key, 1987). 
La presente investigación se propuso encontrar evidencia empirica experimental que, en un ambiente controlado, pusiera a prueba el posible impacto persuasivo de los estímulos eróticos en la publicidad dirigida a jóvenes, al igual que verificar la posible percepción inconsciente de estímulos subliminales y la posible interpretación inconsciente de simbolos sexuales ocultos en las piezas publicitarias. El trabajo consistió en aportar datos provenientes de la comprobación científica al debate ético inherente a la utilización de estímulos sexuales en la publicidad.

El área "Persuasión y tendencias de consumo" que hace parte de la línea de investigación "Publicidad, sociedad, cultura y creatividad" del Programa de Publicidad de la Universidad Jorge Tadeo Lozano, viene adelantando proyectos que buscan desarrollar el tema de la persuasión como objeto de estudio e investigación dada la necesidad de la sociedad y del estamento académico de profundizar en el conocimiento de esta forma de influencia interpersonal. Este constituye un tópico de primera importancia en la actividad publicitaria y propagandistica y un campo de análisis critico fundamental para una sociedad que aspira a desenvolverse en un entorno civilizado y tolerante con las diferencias individuales y los diversos estilos de vida que compiten por lograr la adhesión y el apoyo de los ciudadanos. Este empeño aporta a la discusión que los profesionales de la publicidad han comenzado a hacer con respecto a las posibles consecuencias psicológicas y sociales que sus tácticas pueden tener en el público al que van dirigidas y en el público en general, más allá del mero éxito económico materializado en la adquisición de los bienes y servicios que promueven.

En el mundo publicitario es común justificar el empleo de unas u otras tácticas mencionando el éxito que en el pasado ha tenido alguna campaña que utilizó dicha estrategia; sin embargo, en términos estrictos, la conclusión no es lícita por cuanto en estos casos no es posible establecer relaciones lineales de causa y efecto dado que en el éxito de una campaña intervienen muchos factores como el precio del producto, su distribución, los hábitos adquiridos por los consumidores con antelación a la campaña, etc., todo ello sin mencionar que en una misma pieza publicitaria aparecen muchos elementos persuasivos que se combinan entre sí para producir el resultado final; lo anterior puede ocurrir con la música, los colores, la repetición, la simpatía de los personajes, etc.

No es posible atribuir el éxito de toda la campaña a un solo elemento, como tampoco es posible atribuir a un solo aspecto el fracaso de otra. Para poder hacer tal atribución sería necesario aislar el efecto de cada uno de los elementos posibles, cosa que es imposible de hacer en una campaña real, pero es justamente lo que está obligado a hacer el método científico, cuyo proceder consiste en igualar la influencia de todos los aspectos que inciden y observar la incidencia por separado del factor que se está investigando, factor que, en este caso, es el de los estímulos eróticos.

Desde el punto de vista teórico, este proyecto pretendió poner a prueba uno de los conceptos más importantes de la teoría psicoanalítica freudiana: la posible interpretación inconsciente de símbolos. Por definición, la teoria psicoanalitica se ha mostrado reacia a fundamentar sus afirmaciones con el respaldo de la investigación empírica, pues afirma que el método científico reduce a hechos escuetos las complejas vivencias afectivas de las personas, por lo que ha defendido con celo la validez de sus afirmaciones surgidas a partir del diálogo entre el psicoanalista y su paciente en el proceso terapéutico mediante la asociación libre.

No obstante, algunos investigadores han visto que, en ciertos casos, las afirmaciones del psicoanálisis sí son susceptibles de someterse al escrutinio del método científico $y$ lo han hecho, con lo cual han encontrado que, en muchos casos, las afirmaciones del psicoanálisis han resultado comprobadas $\mathrm{y}$, en general, salen bien libradas (Garrison \& Loredo, 2002).

Al poner a prueba piezas publicitarias que contienen simbolos sexuales y emplear técnicas extraídas del psicoanálisis para observar la reacción de las personas a esas piezas, es posible verificar empiricamente si efectivamente los sujetos han incorporado en su exposición a las piezas publicitarias, los elementos eróticos que se encuentran ocultos en ellas. La respuesta a estos interrogantes teóricos constituye un aporte para la comprensión del funcionamiento de la psiquis humana y para el entendimiento de los posibles mecanismos ocultos de la persuasión, aspecto fundamental para pasar a debatir sobre la ética de emplear tales tácticas. 


\section{Objetivo general:}

Explorar la influencia de los estímulos eróticos, explícitos, de tipo simbólico inconsciente, y subliminales en la publicidad desde las perspectivas de su impacto persuasivo y de responsabilidad social.

\section{Resumen del marco de referencia}

\subsection{Psicoanálisis e investigación científica}

Validar o refutar algunas de las nociones más importantes que sustentan la doctrina psicoanalítica freudiana sigue siendo una tarea inconclusa para la ciencia psicológica. Desafortunadamente, las intensas polémicas que tuvieron lugar décadas atrás, pocas veces estuvieron acompañadas de actividad investigativa que ayudara a mediar en el debate. Con todo, los aportes al conocimiento y a la comprensión de la naturaleza humana de Sigmund Freud continúan siendo difundidos y propiciando álgidas discusiones.

Los aportes de Freud se extendieron a muchos temas y se prolongaron en el tiempo por más de cuarenta años, lo que produjo que sus ideas y planteamientos sufrieran muchas revisiones y correcciones. De otra parte, después de su muerte, sus discipulos y seguidores continuaron haciendo aportes que han quedado inmersos en lo que se conoce como psicoanálisis freudiano, aunque algunas de esas ideas no fueron desarrollos hechos directamente por el propio Freud. Adicionalmente, el psicoanálisis freudiano se complementa y contradice con otras vertientes del psicoanálisis como las que se inspiran en otras figuras más o menos cercanas al pensamiento de Freud como Adler, Jung, Horney, Fromm y Reich, entre otros.

En un intento de sintetizar el pensamiento freudiano, se puede decir que su teoría se funda en dos pilares básicos: el determinismo psíquico y la existencia del inconsciente (Brenner, 1964).

El determinismo psiquico es una noción sustancial que le sirve de soporte a muchas de las afirmaciones más polémicas del discurso psicoanalítico. Se trata de un postulado general que implica que los procesos que son objeto de estudio de la ciencia psicológica no ocurren por azar o como resultado de generación espontánea. Para el psicoanálisis es esencial que, por ejemplo, el más simple y fugaz pensamiento concebido por cualquier persona sea el efecto de la acción de un evento o de una combinación de eventos que lo producen.

Para cualquier persona que haga un poco de introspección, es fácil observar la volatilidad de sus propios procesos intrapsíquicos y es casi natural suponer que ocurren porque simplemente es así, sin razón aparente. El psicoanálisis, por el contrario, considera que el que no seamos capaces de establecer las causas de nuestros procesos mentales no significa que esas causas no existan; puede que las causas sean irrelevantes, que sean casi imposibles de rastrear o que no valga la pena realizar tal esfuerzo, pero las cosas tienen que ocurrir por alguna causa, pues de no ser así, se estaria rompiendo toda la concepción mecanicista y biologista del universo que predominaba en el campo de la ciencia médica a finales del siglo XIX, momento histórico que fue el entorno en el que se cultivó el pensamiento de Freud.

En el tema general del determinismo, se evidencia, al igual que en muchos otros casos, la diferencia entre las ciencias naturales y las ciencias humanas y sociales. En ciencias naturales como la física, la química, la astronomía e incluso la biología, el tema del determinismo encuentra muy poca discusión pues en estos campos la relación causal es evidente en la mayoria de los casos. En las ciencias humanas y sociales, el debate nunca cesa y renace una y otra vez pues al tratarse de disciplinas que pretenden incluirse dentro del calificativo de científicas, no pueden renunciar a la obligación de intentar comprobar hasta donde sea posible sus afirmaciones. Pero la complejidad característica del fenómeno humano y social impide concebir la realidad en modelos mecánicos y lineales y deben buscarse alternativas que permitan entender mejor la estructura y la función de los procesos estudiados, como es el caso de la interpretación de la realidad por medio de analogias en lugar de hacerlo mediante modelos causales (Dethlefsen \& Dahlke, 1998).

La psicología es, por una parte, una ciencia natural por cuanto los procesos psíquicos surgen en la actividad fisiológica del sistema nervioso. También es una ciencia social, por cuanto el entorno cultural humano condiciona y le aporta sentido a cualquier experiencia que un individuo pueda concebir o experimentar. Y también es un campo del saber autónomo e independiente con un objeto de estudio singular y específico, por cuanto los sentimientos, los pensamientos 
y todas las demás experiencias internas existen como tales y tienen una dinámica propia que puede y debe ser estudiada por la ciencia con una metodología adecuada a su naturaleza.

Por todo lo anterior, pasar de hablar de determinismo en general a hablar de determinismo psíquico, es transitar por un camino lleno de grandes obstáculos. El mismo Freud fue muy claro al establecer la importancia capital del determinismo psíquico en su teoría:

\begin{abstract}
Seguramente comenzará por respondernos que tales fenómenos no merecen esclarecimiento alguno, pues se trata únicamente de pequeños accidentes casuales. Mas ¿qué es lo que con esta frase quiere significar? ¿Querrá acaso afirmar que existen sucesos tan insignificantes que se encuentran fuera del encadenamiento de la fenomenologia universal $y$ que lo mismo hubieran podido no producirse? Pero el romper de este modo el determinismo natural, aunque sea en un solo punto, trastornaria toda la concepción científica del mundo. Debemos, pues, hacer ver a quien asi nos contesta todo el alcance de su afirmación, y mostrarle que la concepción religiosa del mundo se conduce más consecuentemente cuando sostiene que un gorrión no cae de un tejado sin una intervención particular de la voluntad divina (Freud, [1916] 1948, p. 67).
\end{abstract}

El determinismo psíquico es una afirmación tan general que sólo se puede abordar en términos generales con un planteamiento filosófico e incluso teológico. Para los practicantes del psicoanálisis como terapia, aceptar el determinismo psíquico es un asunto de concederle credibilidad a un argumento aparentemente lógico con alguna corroboración en la mejoria de los pacientes, pero sin la obligación de comprobar nada según los estrictos requisitos del método científico; para el investigador que intenta ajustarse a criterios de comprobación, las cosas son muy diferentes.

Desde el punto de vista científico, el postulado del determinismo psíquico es de muy dificil manejo. Si en muchas ocasiones se llegase a comprobar objetivamente que los procesos psíquicos efectivamente están determinados por alguna o algunas causas, no se puede afirmar por ello que se trata de un postulado válido por cuanto podrían quedar campos en los que no ocurre y aún no se conocen. Paradójicamente, si una sola vez se comprueba que ocurre un proceso psíquico sin que haya una causa que lo desencadene, se demostraria que el postulado no es tal y que no se puede tomar como un hecho seguro. Sin embargo, demostrar tal cosa es prácticamente imposible en el nivel de desarrollo de la ciencia actual debido a que, cuando se trata del funcionamiento de la mente, rara vez los eventos ocurren por la acción de una sola causa y las causas rara vez tienen un efecto único. Puesto que en las ciencias humanas y sociales lo que se encuentra es una policausalidad multidireccional, el establecimiento de relaciones mecánicas y unidireccionales entre los eventos antecedentes y los consecuentes encuentra muchos tropiezos que son el origen de todas las controversias entre los diferentes enfoques y disciplinas que intentan explicar el acontecer humano.

Con todo, la noción del determinismo psíquico es indispensable para comprender el abordaje psicoanalitico de los procesos internos de la psiquis de las personas, especialmente de los afectivos. Cuando en la práctica del psicoanálisis como terapia, por ejemplo, se intenta comprender el significado de un sueño y se asume que el sueño es la expresión de los motivos latentes e inconscientes de la persona, pues en el fenómeno onírico estaría la clave para comprender la problemática personal del paciente y encontrar su posible cura, se está desarrollando toda una concepción de la situación y una elección de las acciones a realizar fundadas en la aceptación incondicional del postulado del determinismo psíquico. Afortunadamente, no todas las afirmaciones que conforman el cuerpo teórico del psicoanálisis son tan esquivas a los intentos de comprobación mediante el método científico.

El segundo postulado de la doctrina psicoanalitica freudiana es la existencia de motivos inconscientes. La importancia de este segundo postulado también es muy grande debido a que, de ser cierto, implica que las personas muchas veces desconocemos las verdaderas causas de nuestro comportamiento y por lo tanto no seriamos plenamente responsables de él.

Freud no fue el primero en hablar de la posible existencia del inconsciente pues ya los antiguos filósofos griegos habian sugerido 
nociones que implican que el ser humano puede, en ocasiones, no darse cuenta de lo que hace, dice, capta, piensa o siente; o puede no conocer los verdaderos motivos por los que se comporta de una forma $u$ otra. Pero aunque no fue el creador del término ni del concepto, Freud sí fue el encargado de difundir tal idea en los tiempos modernos.

Para entender el sentido en el que Freud se refería al inconsciente, es necesario entender el conflicto interno que, según su visión, siempre estaria desarrollándose en el espacio interno de cada persona entre las fuerzas que conforman su famosa estructura de la personalidad adulta integrada por el ello, el yo y el superyó.

Cuando un bebé llega al mundo, su aparato psíquico estaría conformando únicamente por el ello, la fuente original de la que emana la energía que requiere para funcionar la conciencia humana. En su etapa inicial, el individuo sólo busca satisfacer sus instintos atávicos, herencia de la evolución de la especie, que tienen únicamente la función de obtener placer y evitar el displacer. Si un individuo no recibiera educación alguna y no estuviera expuesto a las presiones de la sociedad, representada en la familia, su vida sería igual o incluso más primitiva que la de los cavernícolas, es decir, sólo atendiendo a lograr la supervivencia propia y la de la especie, procurándose el máximo de placer y el minimo de displacer con un criterio totalmente egoísta.

Pero somos seres sociales, lo cual implica que todos los bebés son sometidos al proceso de la socialización en la que recibimos una intensa presión para vivir de acuerdo a los preceptos imperantes en cada cultura, y comportarnos tal y como esperan las personas de nuestro entorno más cercano. El resultado de este largo proceso de sometimiento a las exigencias sociales, implica un proceso de interiorización de los patrones culturales por parte del individuo que termina por aceptar que las conductas, sentimientos y pensamientos proscritos por su entorno, realmente son malas, inadecuadas y anormales, aún cuando esto implique renunciar a la satisfacción de sus pulsiones naturales.

Cuando este proceso está más o menos culminado, hacia los seis años, el individuo ya no sólo tiene un ello, sino un yo y un superyó. El ello siempre ha estado y estará allí, pero ahora está restringido a expresarse sólo de manera parcial aunque siempre será nuestra verdadera y auténtica naturaleza: los instintos naturales primitivos.

El superyó, a pesar de ser un agregado posterior y una entidad artificial, no deja de ser una fuerza muy poderosa dentro de la psiquis de las personas. En síntesis, el superyó representa la parte moralista de nuestra personalidad, el ideal de lo que deberíamos ser si fuéramos lo que pretendieron nuestros padres cuando nos inculcaron sus mejores valores y aspiraciones, y lo que nosotros mismos anhelamos alcanzar cuando nos imponemos metas de perfección.

El yo, por su parte, es la dimensión racional, realista y adaptativa de nuestra personalidad. La función del yo consiste en mediar y conciliar entre las fuerzas antagónicas del ello y del superyó. Esta mediación consiste en complacer un poco a los dos antagonistas y en restringirlos también un poco. Se trata de satisfacer los instintos primitivos pero sólo en momentos en que hacerlo no representa enfrentar la sanción social $\mathrm{y}$, sobre todo, la autosanción por cuanto la interiorización de las normas sociales no sólo conlleva creer en que ciertas conductas son malas y pecaminosas sino sentirse culpable cada vez que las infringimos.

Cuando un individuo no necesita de vigilancia externa para mantenerse dentro de lo permitido por el grupo social en el que vive, sino que posee controles morales internos que le impiden comportarse inadecuadamente, cuando aplaza la satisfacción de sus instintos primitivos hasta encontrar el momento en el que la sociedad permite tal satisfacción sin que existan sanciones ni sentimientos de culpa, estamos ante una persona con un yo fuerte que tiene bajo control a su ello y a su superyó, es decir a una persona adaptada a su entorno social y cultural, regida por lo que Freud llamó el Principio de Realidad que necesitó varios años de socialización para reemplazar al primitivo Principio de Placer.

Pero estas fuerzas no son estáticas, su enfrentamiento se pone en actividad cada vez que la persona tiene que tomar decisiones en la vida. El conflicto interno implica siempre la tentación de dejarse llevar por los impulsos egoístas que reclaman asegurarnos las experiencias placenteras o controlarnos y, quizás, conformarnos con la satisfacción de vernos como seres cercanos a nuestros ideales de perfección. Si una 
de estas dos fuerzas predomina de una manera demasiado marcada sobre la otra, significa que el yo es débil y la persona cae en alguna de las modalidades del desequilibrio mental.

En esta concepción se considera que para poder ejercer su función de mediación y regulación de las fuerzas antagónicas del ello y el superyó, el yo tiene que recurrir en ocasiones a eliminar de la conciencia ciertos contenidos psíquicos que le resultan conflictivos y generadores de sufrimiento ocasionándole serias pérdidas de la autoestima. Por supuesto, tales contenidos siempre estarian relacionados con los impulsos instintivos y egoístas del ello que resultan inaceptables a la luz de los altos ideales morales interiorizados que conforman el superyó. En otras palabras, una parte de nosotros, la moralista, no puede convivir sin sufrimiento con otra parte, la hedonista. Por tal motivo el individuo recurre al autoengaño, que consiste en negarse a poner en el primer plano de la conciencia los recuerdos de aquellos sucesos cuya evocación resulta excesivamente dolorosa. No obstante, tal eliminación tiene un costo: conlleva una pérdida de contacto con la realidad. La persona no puede ser objetiva con respecto a tales contenidos y su capacidad de adaptación a las circunstancias del entorno sufre una disminución, es decir, su yo es ahora menos fuerte. En ocasiones, el procedimiento no consiste en eliminar de la conciencia el suceso doloroso, mecanismo al que Freud denominó "represión", sino que a los sucesos se les recuerda pero desprovistos de su carga emocional, es decir la persona se convence a sí misma de que el asunto no le produjo sufrimiento alguno.

Las llamadas "lagunas" o amnesias temporales, ocasionadas por el alcohol u otras sustancias que obviamente alteran el mecanismo neurofisiológico que el cerebro pone en juego habitualmente para fijar los recuerdos, evidencian claramente que en términos del sistema nervioso es posible procesar los contenidos psiquicos de diferentes maneras. Esto encuentra confirmación cuando se tiene en cuenta que las amnesias temporales también se presentan en casos de extrema tensión emocional sin que hayan ocurrido golpes o sin que intervengan sustancias psicoactivas.

Freud había incluido sus nociones de represión e inconsciente desde la época de sus observaciones de actos hipnóticos efectuados por Charcot y había consolidado su punto de vista observando y analizando a sus pacientes, pero conceptos tan importantes siempre necesitaron una corroboración más sustancial y fue necesario que pasaran décadas y se obtuvieran pruebas empíricas de campos diferentes al psicoanálisis para que la existencia del inconsciente fuera aceptada por la comunidad científica.

La noción freudiana del inconsciente siempre implicó que el contenido reprimido no desaparecía del campo psíquico del sujeto sino que, aunque la persona no tuviera noticia de él, continuaba luchando por encontrar su expresión en la conciencia y, sobre todo, por encontrar su plena satisfacción mediante la conducta, especialmente cuando se trataba de los instintos primitivos sexuales y violentos de tipo inaceptable y vergonzoso.

Freud dejó claro que el inconsciente encontraba formas de expresarse sin que el individuo pudiera reconocer el contenido problemático. Tal expresión ocurriria por medio de los sueños, de los actos fallidos, de los mecanismos de defensa del yo, de la hipnosis, del arte, de los chistes $\mathrm{y}$, por supuesto, de los sintomas neuróticos.

Nutriéndose de estas fuentes y de otras, la psicología moderna plantea el problema de una manera más general al referirse a los "estados alterados de la conciencia" que conforman un capítulo aparte en muchos de los libros de texto de Psicología general que se publican actualmente (Feldman, 1998; Garrison \& Loredo, 2002).

El concepto de los estados alterados de la conciencia incluye, además, el dormir, las experiencias resultantes del uso de sustancias psicoactivas, la meditación y las experiencias misticas, los trastornos disociativos, las ensoñaciones y las emociones extremas, entre otros.

Los estudios neurofisiológicos han encontrado evidencia objetiva de algunos de estos estados alterados de la conciencia. Tal cosa ha ocurrido con la disociación propia de la llamada "personalidad múltiple" en la que se observó que los sujetos presentan diferentes ondas cerebrales en los momentos en los que están en la superficie las diferentes personalidades (Morris, 1987).

Pero algunos autores consideran incluso que los estados alterados predominan en el tiempo 
sobre los no alterados, expresando con ello que la mayoría de las veces las personas se encuentran en un estado mayor o menor de distracción o "trance" por cuanto están divagando en su mundo interior, dejando de estar plenamente conscientes de los sucesos del entorno (Inglis, 1995). Esta afirmación resulta más comprensible si se tiene en cuenta que el cerebro sólo está plenamente alerta en períodos muy cortos de tiempo en los que se demanda un grado alto de atención, pero, posteriormente, entra en otro tipo de ondas como las alfa que se presentan cuando una persona está tranquila, sentada o acostada con los ojos cerrados. Si la persona, aún tranquila, abre los ojos, las que aparecen son las ondas beta que poseen una mayor frecuencia. Cuando la persona se encuentra profundamente dormida, las ondas que se registran son del tipo delta, de frecuencia aún más baja (Morris \& Maisto, 2001).

En la teoría freudiana, la represión de los contenidos conflictivos enviados al inconsciente cumple una función defensiva, pero en otros autores la noción presenta connotaciones diferentes. Jean Piaget, por ejemplo, planteó en la década de los setenta, que su consideración del inconsciente es paralela a la del psicoanálisis por cuanto el inconsciente para él es de tipo cognoscitivo en tanto que el psicoanalítico es de tipo afectivo, llegando a pronosticar que el desarrollo de la ciencia psicológica permitiría llegar en un futuro a encontrar un punto de fusión entre las dos visiones (Piaget, 1980).

Otros enfoques han documentado y aportado evidencia empírica acerca de procesos psíquicos en los que la persona se engaña a sí misma y pierde su objetividad con el propósito de proteger su autoestima. Estos desarrollos tienen puntos de encuentro mayores o menores con la concepción freudiana. Tal es el caso de la teoría de la disonancia cognitiva de Leon Festinger (1957, citado por Mann, 1973) quien, desde la perspectiva de la psicología social, demostró experimentalmente procesos muy parecidos a aquellos que los psicoanalistas denominan racionalización.

La racionalización es uno de los mecanismos de defensa del yo más importantes al punto de acompañar a todos los demás cuando son usados; así, cuando una persona hace un desplazamiento, una proyección o una compensación por ejemplo, no sólo tiene que utilizar la represión que, como ya se explicó, consiste en eliminar de la conciencia los contenidos que generan sufrimiento, sino que el sujeto también tiene que darse razones y creérselas para poder justificarse ante sí mismo y continuar teniendo una visión coherente de sí.

De esta manera, por ejemplo, si una persona que en el fondo tiene un fuerte sentimiento de inferioridad avivado porque un vecino compró un auto nuevo, puede intentar compensar dicho sentimiento y comprar un auto aún mejor, pero esta persona puede que nunca reconozca cuál fue la verdadera motivación de lo que hizo. Primero olvidará que hizo la compra para evitar sentirse inferior a su vecino y segundo buscará y encontrará otras razones que le permitirán justificar por qué actuó de esa manera. Dirá, por ejemplo, que había que renovar la inversión, que habia que salir del auto anterior antes que empezara a fallar, etc. Pero lo más importante es que el individuo queda convencido de que esas fueron las verdaderas razones. El mecanismo funciona precisamente porque es inconsciente.

Leon Festinger encontró y demostró experimentalmente la existencia de procesos similares investigando el cambio de actitudes. Comprobó que las personas buscan información sobre ventajas y desventajas de hacer algo y son mucho más objetivas y ponderadas antes de tomar una decisión que lo que lo son después de haberlas tomado. Antes de elegir, la persona le asigna mayor peso a los argumentos que favorecen escoger la alternativa A que el que le asigna después de haberse decidido por la alternativa B. Con la alternativa B ocurre lo opuesto: se le asigna mayor peso después de haberla elegido que el que se le asignaba antes. La razón: auto justificarse y convencerse de que se escogió correctamente. Festinger (citado por Baron \& Byrne, 2002) también encontró que las personas pueden considerar una ventaja o desventaja como más o menos importante dependiendo de cuál opción permita conservar en alto la autoestima.

Cuando un individuo racionaliza, lo que hace es maximizar la importancia y el peso "probatorio" de aquello que le conviene y minimizar lo que no le conviene y queda convencido de tener la razón de su parte. Un ejemplo que muestra hasta qué punto puede llegar este mecanismo es el de la persona que compra lotería. Puesto que el individuo quiere ganar, no tiene problema en desconocer la altísima probabilidad de no ganar y enfatizar la ínfima posibilidad de 
ganar y aferrarse a la fantasía de lo que hará con el dinero que ganará. Si la persona fuera realista, nunca gastaría su dinero en lotería, pero en ocasiones el autoengaño resulta más placentero que enfrentar la realidad.

Edgar Morin (2000), también se refirió al mismo mecanismo mental en la discusión de los temas ciudadanos. El nombre que le asignó al fenómeno fue el de "egocentrismo", al que calificó como uno de los mayores impedimentos para el ejercicio de una verdadera democracia. La conclusión es que preservar la autoestima puede ser, y muchas veces es, más importante que acceder a la verdad o a la justicia.

Durante muchos años, el escenario teórico de la psicología vivió el debate entre los teóricos que aceptaban la existencia del inconsciente y los que no lo hacian. Este debate conlleva muchos más puntos de conflicto, especialmente en lo concerniente a la aceptación del rigor de la metodología de investigación según los criterios del positivismo que exige que la ciencia sólo se ocupe de los fenómenos observables, medibles y cuantificables. Tal exigencia dificultaba el estudio de todos los procesos intrapsíquicos y mucho más en el caso de los que se ubicaban en la categoría de inconscientes.

Quienes exigian el apego a los cánones del positivismo llegaron a tildar las ideas psicoanaliticas de literatura o mentalismo. Hoy en día, sin embargo, muchos de los partidarios de posiciones tan radicales cedieron poco a poco e incluyeron el estudio de los procesos cognoscitivos y algunos otros procesos intrapsiquicos, pero siempre ajustándose al rigor del método científico.

Por otra parte, desde diversas perspectivas se fue acumulando evidencia empirica que puso de presente que los procesos inconscientes son un hecho incontrastable dado que la evidencia que lo sustenta es del tipo fisiológico, cosa que trasciende todos los reparos que con mayor o menor razón se elevaban en el pasado.

En primer lugar, hoy en día es imposible negar la evidencia de las experiencias serias y controladas que se han hecho sobre los procesos hipnóticos en los que los pacientes son sometidos a procesos dolorosos como quema-duras o pinchazos sin que reaccionen a ellos, lo que demuestra que es posible eliminar de la conciencia una sensación dolorosa, aunque no se pueda dar una respuesta satisfactoria de cómo y por qué ocurre semejante fenómeno (Erickson, Hershman \& Secter, 1990, citados por Feldman, 1998).

Con alguna relación con la supresión de las sensaciones del dolor, se encuentra un segundo grupo de pruebas empíricas sobre la existencia del inconsciente; este grupo está constituido por una multitud de investigaciones que muestran la realidad del llamado efecto placebo, en el que a una persona se le administra una droga falsa acompañada de instrucciones que sugieren que se trata de una droga muy poderosa que aliviará el dolor. Inexplicablemente las personas manifiestan no experimentar el dolor. Se cree que las endorfinas, neurotransmisores bloqueadores del dolor, hacen su aparición como consecuencia de la certeza de la persona de que no va a sentir el dolor. La importancia de los placebos en la historia de la medicina es tal, que en las investigaciones sobre nuevos medicamentos, a los investigadores ni siquiera se les toma en serio cuando no hacen pruebas para establecer una comparación entre los efectos del medicamento en cuestión en comparación con el efecto placebo (Shapiro, 1971). El poder del efecto placebo no se limita a eliminar el dolor sino que llega a suprimir o invertir el efecto de poderosas drogas (Pérez, 1978), e incluso se conocen casos de individuos adictos a los placebos (Byerly, 1976). También se ha encontrado que los placebos pueden inducir un aumento o un descenso en el rendimiento de un deportista que cree estar dopado o que cree estar bajo el efecto de una droga que le resta fuerzas (Mastrodoménico, 1979).

\subsection{Percepción inconsciente}

Un tercer grupo de pruebas empíricas sobre la existencia de procesos psíquicos inconscientes se encuentra en las investigaciones sobre la recepción de estímulos presentes en el ambiente físico del sujeto sin que éste tenga noticia de su presencia y de su efecto sobre sus procesos mentales. Tal recepción incluye a los estímulos subliminales o subumbrales y la recepción de las feromonas humanas.

\section{-Percepción subliminal.}

Uno de los casos más debatidos en la historia de la psicología de la publicidad es el famoso experimento supuestamente realizado en 1957 en un cinema de New Jersey en el que 
James Vicary, un investigador de mercados, afirmó que utilizando un aparato llamado taquistoscopio, que permitía sobreponer una imagen que destellaba a gran velocidad sobre la proyección de una película, logró producir cambios apreciables en la conducta de compra de los asistentes expuestos al procedimiento. Aunque las personas no podian captar nada realmente, debido a la excesiva velocidad, el mensaje estaba allí. Se trataba, cuentan muchos autores (Ross, 1978; Packard, 1973; Key, 1987), de un texto en el que se leía: "Coma palomitas de maíz" y otro que decía "Tome Coca Cola". Supuestamente el mensaje fue exhibido ante casi 46.000 personas. Vicary afirmó públicamente que las ventas de maíz aumentaron un $57,5 \%$ y las de Coca Cola en un $18,1 \%$. Posteriormente, el señor Vicary fue desacreditado, reconoció que había inventado los datos y finalmente desapareció. El paso del tiempo permitió establecer que se trataba de un estafador que timaba a las empresas prometiendo aumentos significativos en las ventas con procedimientos ocultos respaldados con experimentos que nunca realizó (Blackwell, Miniard, \& Engel, 2002; Wells, Burnet, \& Moriarty, 2007).

La historia de Vicary fue difundida y debatida por décadas (Feldman, 1998), no sólo en el campo académico de la psicología sino en el de la opinión pública, debido a su utilización por parte de grupos religiosos que se han propuesto denunciar la supuesta inclusión de mensajes satánicos en la música que se escucharian al hacer sonar las canciones al revés. En estos casos, el propósito de denunciar algo se convierte en su principal impulso, pues para darle credibilidad a las supuestas manipulaciones satánicas había que dejar establecida la eficacia de los mensajes que llegan directamente al inconsciente para influir sobre la conducta de las personas.

Para el mundo académico, la importancia del tema de lo subliminal radica en que por mucho tiempo se creyó que este experimento demostraba de manera objetiva, es decir observable, medible y cuantificable, la existencia del inconsciente, tema que siempre fue el punto más álgido de la discusión en la comunidad psicológica entre las llamadas teorias psicodinámicas y los partidarios de las teorias del aprendizaje que siempre alegaron ser los verdaderos representantes de la ciencia en el campo psicológico, pues todas sus afirmaciones siempre se basaron en hallazgos experimentales. Si resultaba cierto que las personas pueden "ver" algo que no es visible y que se puede influir en la conducta sin que la persona se percate de ello, quedaba demostrado, según rigurosos procedimientos científicos, que efectivamente existen procesos mentales inconscientes.

Un principio de la persuasión nos dice que cuando las personas quieren creer creen, incluso sin pruebas; y cuando no quieren creer no creen, incluso con pruebas. El tantas veces citado "experimento" de Vicary, junto con algunas experiencias controladas en el campo de la hipnosis y los innumerables estudios experimentales sobre el efecto placebo, fueron durante mucho tiempo lo único en que podían basarse los defensores de la existencia del inconsciente para respaldar sus afirmaciones en la misma lógica de sus adversarios.

No obstante el fiasco del señor Vicary, el interés por el tema de la percepción subliminal no decayó y con el paso del tiempo un buen número de investigadores acumuló evidencias en el sentido de que el fenómeno sí ocurre y es posible probarlo objetivamente. Hoy en día la mayoría de los autores recono-cen como un hecho objetivo, incluso con fundamento en evidencia de tipo neurofisiológico, que el ser humano puede captar, sin darse cuenta, los estímulos subliminales; pero también se ha hecho evidente que la capacidad de estos mensajes para influir sobre la conducta de las personas es muy pequeña y solamente se produce en circunstancias muy favorables, como la de efectuar una conducta sin relevancia y con la que la persona concuerda (Feldman, 1998; Assael, 1999; Morris \& Maisto, 2001; Garrison \& Loredo, 2002).

Focalizando el tema en el campo de la recepción inconsciente de estimulos, hay que distinguir dos procesos diferentes en los cuales hay evidencia objetiva que respalda la aseveración de que estos procesos pueden ocurrir sin que el sujeto se dé cuenta de ello, e incluso afectar su conducta. Por una parte está la evidencia que se ha podido recolectar en muchos años de investigación sobre los estímulos subliminales después de las peripecias del señor Vicary; y de otra parte tenemos la recepción de los estímulos químicos de las feromonas que son captados por la personas mediante la participación del órgano vómero nasal sin que éstas tengan percatación alguna de su presencia, proceso que indudablemente afecta la conducta (Takami \& otros, 1993, citados por Morris \& Maisto, 2001). 
De hecho, las investigaciones serias sobre la ocurrencia de estos fenómenos se remontan a una época anterior pues ya en la primera mitad del siglo XX, los neurofisiólogos soviéticos habian encontrado evidencia empírica de ciertos procesamientos neuronales que tenían como resultado que el individuo no fuera consciente de sus experiencias.

Para tener conciencia exacta de las cualidades de los objetos que influyen sobre nosotros, es condición indispensable que la excitación que llega a las células corticales del analizador se trasmita a las células corticales que intervienen en las funciones del lenguaje. Solamente entonces podemos hacer acto de conciencia del estímulo que ha actuado, denominarlo con la palabra y, si es necesario, comunicar a los demás acerca de ello. En algunos casos, la excitación que abarca las células corticales de un analizador determinado no se transmite a las células conectadas con los estímulos verbales. Entonces el estímulo que ha actuado no se hace acto de conciencia para nosotros. Sin embargo, también en este caso, como lo han demostrado los experimentos de Herschuna, puede motivar algunas reacciones (Smirnov, Leontiev, Rubinshtein, \& Tieplov, 1960, p. 99).

En 1951, Lazarus y McCleary publicaron un estudio en Psichological Review que daba cuenta de experimentos controlados con sílabas sin sentido acompañadas de choques eléctricos. La experiencia demostró que los sujetos habian "identificado" los estímulos inconscientemente (Lazarus \& Mccleary, 1951, como se cita en Ross, 1978). El mismo autor cita también a Douglas Gibb (1966), quien pudo documentar experimentalmente ciertos cambios en la conducta como consecuencia de la exposición a sugerencias subliminales sobre el prestigio que se presentaron superpuestas en unas videocintas.

Robert Feldman (1998) cita a Bargh y Pietromaco (1982) y a Merikle (1992), quienes también demostraron experimentalmente que las personas que son expuestas muy brevemente a información de la que no pueden dar cuenta, de todas maneras se ven influidas por ella. Algo análogo ocurrió en las investigaciones rigurosamente controladas de Nuberg, (1988, citado por Morris \& Maisto, 2001), en las que palabras relacionadas con rivalidad y competencia eran exhibidas a altísimas velocidades de modo que las personas no pudieran verlas, con lo que se evidenció que dichas palabras indujeron comportamientos muy competitivos.
E1 mismo autor cita a Erdley y D'Agostino (1988) quienes exhibieron subliminalmente a un grupo, palabras asociadas con honestidad y ante otro grupo palabras asociadas con maldad. Cuando se les pidió a los sujetos que calificaran la conducta de la mujer, cada grupo lo hizo acorde con la información subliminal que recibió antes. Lo mismo puede decirse la exposición subliminal a frases alentadoras de Hardaway (1991).

Estos y otros estudios análogos que se pueden encontrar en la literatura científica, han acumulado suficiente evidencia empírica que permite afirmar sin cortapisas que la percepción subliminal es un hecho comprobado. No obstante, no resulta fácil decir lo mismo de la persuasión subliminal y de otra gran cantidad de fenómenos de los que se habla, asociándolos sin fórmula de juicio con este concepto.

La palabra subliminal quiere decir literalmente por debajo del límite, pero no del límite de la conciencia, que es un concepto muy dificil de definir y mucho más de respaldar con evidencia objetiva; el límite del que se está hablando es el límite de la experiencia sensorial, es decir, el umbral absoluto de la sensación, la intensidad minima que debe poseer un estímulo para ser detectado.

Cuando un estímulo no alcanza la intensidad necesaria para producir la sensación, obviamente la persona no se percata de su presencia aunque éste de todas maneras está alli. La pregunta que ha encontrado respuesta afirmativa con la investigación científica de muchos años es la de si, de todas maneras, el estímulo que se encuentra por debajo del umbral absoluto es captado mediante algún mecanismo no consciente por la persona; y si, bajo ciertas condiciones, dicho estímulo puede producir cambios en el comportamiento de las personas.

Con todo, la opinión de los críticos de la publicidad y la sociedad de consumo, como Vance Packard y Wilson Bryan Key, en cuanto a que los mensajes subliminales son ampliamente usados por los profesionales de la persuasión, es compartida por autores menos beligerantes y más contemporáneos. Tal es el caso de Roger Blackwell y sus colaboradores Paul Miniard y James Engel (2002), quienes afirman: 
En nuestros dias, el uso de estimulos subliminales es común. Los consumidores gastan millones de dólares todos los años en cintas de aprendizaje autodidacta que contienen mensajes subliminales. Las peliculas de horror incluyen ocasionalmente máscaras de muerte y otras imágenes subliminales de miedo para aumentar el efecto de terror en los espectadores. Los minoristas algunas veces incorporan mensajes subliminales en la música de la tienda, para motivar a los empleados y reducir los robos. Algunos centros vacacionales también han probado los mensajes subliminales para hacer que los turistas se relajen.

Estos autores también terminan concluyendo que el uso prevaleciente no prueba la supuesta influencia sobre el consumidor, reconocen que en algunas condiciones la investigación ha evidenciado efectos modestos en la conducta, pero insisten en la falta de evidencia contundente sobre la supuesta eficacia de este tipo de mensajes para influir de manera decisiva en la conducta real.

Igualmente, adhieren a la opinión de varios escritores sobre el tema que han revisado la copiosa información recabada a lo largo de los años, quienes afirman que los estímulos persuasivos que son percibidos conscientemente por la persona poseen una mayor eficacia que los que no alcanzan el umbral, pues la debilidad de estos últimos hacen que sus efectos potenciales sean fácilmente nulificados por los estímulos más fuertes que compiten con ellos.

-El órgano vómero nasal.

$\mathrm{Si}$, además de lo ya mencionado sobre los estímulos subliminales, se tiene en cuenta que existe otro fenómeno de recepción inconsciente de estímulos, el debate sobre la existencia de procesos sensoperceptivos inconscientes queda definitivamente cerrado. De hecho, la prueba empírica más contundente sobre la existencia de procesos psíquicos inconscientes provino de una fuente inesperada: las investigaciones sobre anatomia y fisiologia humana. En efecto, los investigadores se habian preguntado durante mucho tiempo si las feromonas que juegan un papel central en la atracción sexual de muchas especies animales también podian jugar un papel similar en los humanos.

Aunque en los años setenta ya se tenía evidencia de que las mujeres que conviven juntas tienden a sincronizar sus ciclos menstruales y se pensaba que las feromonas debian participar en este proceso, no se podía explicar el fenómeno por el cual la inmensa mayoria de las personas no logran experimentar el olor que eventualmente despiden las glándulas sexuales de las demás personas (McClintock, 1974, como se cita en Garrison \& Loredo, 2002). No obstante, los anatomistas hallaron un nuevo órgano de los sentidos al que denominaron órgano vómero nasal que resultó ser un dispositivo sensorial que opera todo el tiempo inconscientemente al punto que sólo en los últimos años se vino a saber de su existencia (Takami et al., 1993, citado por Morris \& Maisto, 2001). Este órgano reacciona a la presencia de las feromonas de las personas del sexo opuesto y produce leves cambios en el comportamiento y en el estado de ánimo sin que se tenga noticia alguna del estímulo que los está desencadenando.

\subsection{Simbolismo inconsciente}

Captar un estimulo presente en el ambiente sin tener noticia de ello es un proceso psíquico diferente a interpretar un símbolo sin percatarse de estarlo haciendo. El tema específico de los simbolos inconscientes fue tratado en extenso por Freud refiriéndose al tema de los sueños. Al concederle importancia al proceso onírico atribuyéndole un significado, Freud estaba arriesgándose a poner al psicoanálisis a la altura de las creencias populares y el animismo, pero su convicción lo llevó a seguir adelante a pesar de las fuertes críticas.

Para Freud ([1916] 1948), los sueños son expresión de los contenidos reprimidos en el inconsciente y por supuesto son manifestación de los deseos del ello que más vergüenza suponen para el superyó. Esos contenidos constituyen los motivos latentes, que a pesar de tratarse de un estado diferente al de la vigilia no pueden acceder a la conciencia en su estado puro, sino que son distorsionados en una especie de solución de compromiso llevada a cabo por el yo en su función de complacer y restringir parcialmente a los antagonistas y en su intención de continuar con el necesario descanso del acto de dormir. Lo que resulta de esa mediación es el contenido manifiesto 
del sueño, es decir lo que la persona puede recordar de la experiencia al despertar, y el material con el que se trabaja en la terapia a la hora de intentar la interpretación.

Al plantear la noción de dos contenidos relacionados, el latente y el manifiesto, uno de ellos inconsciente y el otro consciente, uno vergonzoso y otro aceptable para el superyó, necesariamente hay que suponer una especie de transición o traducción del uno al otro, y ése precisamente es el papel que cumple el símbolo onírico.

Freud se cuidó mucho de combatir la creencia popular de que los símbolos de los sueños fueran universales, es decir que un elemento aparecido en el sueño de una persona significa igual cosa que ese mismo elemento en el sueño de otra persona. Insistió en que los símbolos de los sueños eran personales y que una gran parte de la labor de interpretación de los sueños en la terapia psicoanalítica pasaba por descubrir el significado de cada símbolo para ese paciente; por supuesto él reconocía que al ser parte de una misma cultura podría ocurrir una cierta homogeneidad en la utilización de un mismo símbolo por parte de diversas personas, pero siempre se necesitaba la labor de interpretación personalizada para verificar el significado (Freud, [1916] 1948).

Quizás debido a que Freud vivió en la época victoriana en la que el tema de la sexualidad era considerado inmoral y era de mal gusto tratarlo públicamente, o quizás, como sugieren algunos, por sus conflictos interiores, terminó privilegiando los contenidos sexuales considerándolos constituyentes fundamentales del inconsciente, el almacén de instintos y deseos reprimidos por su carácter vergonzoso: “(...) ha de pareceros sorprendente que el simbolismo no sea en todos los demás sectores necesario y únicamente sexual, mientras que en los sueños sirven los simbolos casi exclusivamente para la expresión de objetos y relaciones sexuales" (Freud, [1916] 1948, p. 142). Sin embargo, la importancia de lo sexual para Freud iba más allá de los sueños y llegó incluso a atribuirle el origen del lenguaje (Freud, [1916], 1948).

Pero a Freud no se le pasaba por alto que si aceptaba la noción de un simbolismo inconsciente, se estaba saliendo del terreno en el que siempre se había movido: el estudio de la afectividad humana. Al estudiar cualquier proceso simbólico se estaba introduciendo en el terreno de los procesos cognoscitivos. Esto es así porque una cosa es aceptar que la persona elimina de su conciencia un recuerdo o una emoción dolorosa y no se percata de su existencia, y otra cosa es que un individuo en un plano de su ser comprende un significado, pero en otro plano no tiene noticia de él.

\begin{abstract}
Hasta ahora no nos habiamos visto obligados a admitir más que tendencias inconscientes, o sea tendencias que ignoramos durante un lapso de tiempo más o menos largo. Pero esta vez se trata de algo más, se trata de conocimientos inconscientes, de relaciones inconscientes entre ciertas ideas y de consideraciones inconscientes entre diversos objetos, a consecuencia de las cuales uno de dichos objetos pasa a instalarse de manera permanente en el lugar del otro. Resulta además, que estas comparaciones no son para cada caso diferentes, sino que se hallan establecidas de un modo fijo y dispuestas para ser utilizadas. Prueba de ello es que son siempre idénticas en las personas más distintas y subsisten quizá a pesar de las diferencias de lenguaje (Freud, [1916], 1948, p. 142).
\end{abstract}

Freud dejó consignadas en sus escritos sus observaciones sobre la elaboración de los sueños manifiestos en los que intervienen procesos como la condensación, que consiste en que el contenido latente del sueño es muchos más extenso que el manifiesto en el que se presenta una sintesis muy abreviada.

Esta condensación se realiza por eliminación de algunos materiales, por fragmentación de otros o por fusión de materiales con rasgos comunes. En otros caso el proceso necesario para establecer la significación es el desplazamiento que consiste en que la carga emocional que en el contenido latente está dirigido hacia una persona, por ejemplo, aparezca en el contenido manifiesto, después de haber pasado el tamiz de la censura onírica, atribuido a otra persona con lo que resulta irreconocible y se vuelve aceptable para el soñador. Un tercer mecanismo de elaboración es la representación plástica, que consiste en el reemplazo de ideas por imágenes visuales (Freud, [1916], 1948 , p. 146, 150); de esta manera, por ejemplo, el deseo de conquistar a una dama puede aparecer en un sueño en una escena en 
la que el soñador escala y alcanza la cima de una montaña.

La verificación del vínculo entre el referente y el significado, se obtiene en el psicoanálisis por medio de la asociación libre en la que la cadena de verbalizaciones del sujeto evidencia que en su mente los dos elementos se encuentran relacionados. Por supuesto, comprobar objetivamente tal relación es sumamente difícil y los psicoanalistas no creen que sea necesario hacerlo.

Freud afirmaba que la esencia del simbolismo onírico es una comparación, pero no una comparación cualquiera sino una de tipo limitado. Reconocía que la noción de símbolo era un tanto vaga porque a veces podría entenderse como sustitución o representación e incluso como alusión. Notaba que a veces resultaba sencillo encontrar el factor común que permitía relacionar los dos elementos, en otras ocasiones era de muy dificil consecución y en algunas otras imposible (Freud, [1916], 1948, p. 134).

La labor de interpretación de los sueños de sus pacientes llevó a Freud a concluir que no eran muchos los objetos que necesitaban ser representados simbólicamente en los sueños. Su lista incluía el cuerpo humano en su totalidad, los padres, los hijos, hermanos y hermanas, el nacimiento, la muerte, la desnudez y unas pocas cosas más.

Con frecuencia encontró que la casa aparecía en los sueños manifiestos como representación simbólica del cuerpo humano. Los padres como el emperador y la emperatriz, o el rey y la reina u otros personajes sobresalientes. Los hijos, hermanos y hermanas son representados con frecuencia como animales pequeños o parásitos. El nacimiento por el agua, la muerte por una partida o por elementos oscuros y siniestros. La desnudez por la ropa y los uniformes (Freud, [1916], 1948, p. 134).

Pero cuando se trata de los elementos sexuales se encuentra una gran riqueza de símbolos para representarlos. Los objetos a representar son muy pocos, pero los símbolos son muy variados. Estos son los órganos genitales, los procesos sexuales y el coito.

El órgano genital masculino tenía para Freud un gran número de formas de representación, entre ellas el número tres, los objetos que se asemejan a su forma como los bastones, paraguas, tallos, árboles, etc., o los objetos que tienen la capacidad de penetrar el cuerpo como los cuchillos, sables y demás armas blancas, también las armas de fuego y los objetos de los que manan líquidos como los grifos, jarros y surtidores. Igualmente los objetos que se alargan y las herramientas y máquinas. Los globos y los aviones entran en esta lista por su capacidad de elevarse y lo mismo ocurre con las escenas de vuelo. Otros símbolos fálicos son algunos animales como los reptiles y los peces y, sobre todo, las serpientes (Freud, [1916], 1948, p. 135, 136).

El aparato genital femenino puede aparecer en el sueño manifiesto en forma de cavidades: minas, fosas, cavernas, vasos, botellas, cajas, cofres, bolsillos, etc., especialmente las cajitas de joyas, los barcos, armarios, estufas y también las habitaciones y las puertas. En esta categoria se encuentran además la madera y el papel, las mesas y los libros. Las flores son símbolos vaginales y de la virginidad, no sólo en los sueños sino en las tradiciones populares. Algo similar ocurre con animales como las conchas y los caracoles. La boca es también un símbolo vaginal $\mathrm{y}$, entre los edificios, la iglesia y la capilla deben ser incluidas en esta lista. Según Freud, los paisajes simbolizan todo el aparato genital femenino en su complejidad.

Hablando más en general del cuerpo femenino, en los sueños hay otras partes que también están en la categoría de elementos sexuales como los senos que suelen aparecer como frutas, especialmente manzanas y melocotones. El vello púbico se representa simbólicamente por matorrales y bosques.

Freud argumentaba que estos símbolos llegan a ser comunes a muchas personas porque todos ellos forman parte de fábulas, mitos, folklore, costumbres, chistes, proverbios, del lenguaje poético, del arte y, por supuesto del lenguaje común. En todos estos casos se encuentra el mismo simbolismo que las personas comprenden sin dificultad. Por esto es posible establecer un paralelismo con el simbolismo onírico (Freud, [1916], 1948, p. 138). 


\subsection{Psicología del erotismo en publicidad}

Es bien sabido que la publicidad es un género de la comunicación con características especiales pues, a diferencia de la conversación cotidiana, el mensaje publicitario presenta una pérdida de espontaneidad en el proceso de transmisión, esta pérdida es ocasionada por el tenor abiertamente interesado de los mensajes comerciales. Se trata de una comunicación elaborada con extrema premeditación y un propósito clarísimo de ejercer influencia persuasiva en el receptor. Esto hace que desde su aparición haya sido vista con recelo y, en algunos casos, con aversión.

Los publicistas en su afán por obtener el efecto deseado en su público objetivo, recurren a prácticamente todo lo que pueda ser útil para alcanzar su empeño: inducir a la acción de compra del producto anunciado. Este afán hace admirable a la publicidad pues la convierte en una verdadera vitrina pública de creatividad, ingenio e innovación; en otros casos son notables su buen sentido del humor, su estética, su optimismo y permanente incitación a creer que es posible un mundo alegre y feliz, su apoyo a causas sociales nobles y, en ocasiones, su incitación a que las personas expresen las facetas más elevadas de su potencial. Pero ese mismo afán de producir resultados también lleva a la publicidad a acercarse o traspasar los limites de lo que muchas personas consideran aceptable en términos éticos y estéticos. Estos desarrollos son los que permanentemente hacen que se produzcan polémicas, que paradójicamente pueden resultar teniendo mayor impacto emocional en el consumidor $\mathrm{y}$, por ende, mejores resultados económicos. El empleo de estímulos eróticos en la publicidad es precisamente uno de esos aspectos que eventualmente producen polémica entre el público corriente y entre los autores que se proponen analizar el impacto social de esta actividad en la sociedad moderna.

En el caso del público, la mayoría de los comentarios críticos se orientan en el sentido del llamado rechazo moralizador (Balle, 1991), enfatizando sus efectos disociadores especialmente en los niños y en los jóvenes y expresando preocupación por el posible impacto en la pérdida de valores y en el decaimiento de la sociedad por tales razones.

Curiosamente, algunos comentarios sobre la utilización de los estímulos eróticos en la publicidad que expresan el placer de apreciar cuerpos voluptuosos y atractivos, rostros bellos y situaciones cargadas de sensualidad tienen poca presencia en los debates públicos pero son corrientes en las conversaciones cotidianas. Este hecho podría explicarse por la tendencia de muchas personas a expresarse públicamente con argumentos "superyóicos", y con argumentos hedonistas en los contextos intimos y privados. Algunos definirian esto como una doble moral, pero en términos psicoanaliticos la paradoja descrita sólo expresaria el conflicto intrapsíquico siempre presente en todo ser humano.

Los análisis de los autores que profundizan en los efectos sociales de la publicidad abundan en descripciones de cómo el intento persuasivo erótico envuelve al receptor y lo convierte en consumidor del producto. Vance Packard (1973), quien es considerado por Mucchielli (1977) como uno de los críticos más connotados de la publicidad y de las investigaciones motivacionales, dedica todo un capitulo de su libro Las formas ocultas de la propaganda a analizar el empleo de los estímulos eróticos en las piezas publicitarias. En su abordaje del tema, comienza por mencionar cómo los publicistas siempre han visto los estímulos eróticos como armas poderosas, pero aclara que, por ejemplo, en la década de los cincuenta, el recurso era utilizado únicamente para llamar la atención. No obstante, cuando cobró fuerza el movimiento de la investigación motivacional iniciado por Ernest Ditcher, y debido a su fuerte orientación psicoanalítica, los publicistas y mercadólogos vieron en los estímulos eróticos una forma de influir en la conciencia y en el comportamiento de los consumidores de una manera mucho más profunda y sutil.

Packard afirma que las estrategias eróticas tradicionales, que siempre lograron su impacto limitándose a mostrar más partes del cuerpo humano que las convencionalmente aceptadas, tenian el inconveniente de dejar al comprador desilusionado y resentido, con lo que se afectaban las ventas del producto en una segunda ocasión y, por ejemplo en el caso de los perfumes, se encontraba que sólo se lograba una compra inicial siendo los frascos y recipientes almacenados los que revelaban una falta total de fidelidad a las marcas.

La concepción psicoanalitica freudiana aplicada al comportamiento del consumidor se vio muchas veces reforzada por sus seguidores cuando eran consultados por los expertos en mercadotecnia y se produjo mucha polémica 
cuando se hablaba de la interpretación inconsciente de símbolos fálicos como los labiales o los estilógrafos. En este último caso se analizaban casos como el de un hombre que podría estar interesado en pagar hasta quince veces más el valor de un estilógrafo si éste tenía el poder de hacer significar su superioridad masculina, aunque un producto mucho menos costoso le serviria, en términos prácticos y utilitarios, exactamente para lo mismo. Por supuesto en términos afectivos la diferencia entre los dos productos es fácilmente apreciable.

Packard trae a colación un ejemplo muy ilustrativo de la aplicación a la mercadotecnia de los principios psicoanalíticos relacionados con el poder simbólico de los objetos en los planos más profundos de la psiquis humana. Cuenta Packard que, en los primeros dias de la investigación motivacional, Ditcher fue contratado por la Chrysler Corporation para averiguar por qué los hombres se mostraban muy atraidos por los modelos deportivos y convertibles pero terminaban comprando los modelos familiares, mucho más convencionales. La conclusión de Ditcher fue que los dos tipos de autos representaban simbólicamente a la esposa legítima y a la amante. El auto deportivo despertaba ensoñaciones juveniles de aventuras románticas, pero la dimensión racional terminaba imponiendo su dominio cuando el comprador consideraba que tales cosas son imposibles de llevar a cabo en la práctica y por ello terminaba comprando el auto convencional. El truco de mercadotecnia, entonces, consistía en exhibir en las vitrinas y en las piezas publicitarias los autos deportivos con el fin de producir la atracción inicial, pero sabiendo muy bien que al final los hombres terminarian llevándose el auto familiar. De la misma manera que se sueña con grandes aventuras llenas de disipación y hedonismo, se termina aceptando la presión social y conformándose con una vida convencional. Un desarrollo posterior de la estrategia consistió en desarrollar un auto que combinara lo mejor de ambos aspectos: un auto que conjugara los mejores atributos de la amante y la esposa simbólicas, es decir que si un auto era confiable y seguro pero también romántico, juvenil y aventurero, se tendría el auto perfecto. Tal cosa se consiguió aparentemente con el Hard Top que, según Packard, fue el auto de mayor éxito en muchos años en el mercado norteamericano.

El proceso completo de la mercadotecnia, que logró su máximo desarrollo en las décadas de los cincuenta y los sesenta, consiste en efectuar la indagación acerca de cuáles son los nichos psicológicos profundos, es decir los resortes internos que verdaderamente subyacen tras las conductas de compra. Estos motivos muchas veces son ignorados por la misma persona y de ninguna manera se pueden conocer con técnicas de investigación como las encuestas, que sólo dan cuenta de las razones superficiales de nuestras preferencias. Las técnicas de la investigación motivacional deben trascender el plano de las racionalizaciones secundarias que consiguen hacer presentable ante la sociedad o ante uno mismo lo que en el fondo está motivado por los impulsos primitivos, narcisistas y hedonistas que muchas veces son vergonzosos y generadores de tensión (Mucchielli, 1977).

Las mismas razones nos estarian explicando por qué las técnicas de la investigación motivacional son las mismas que los terapeutas de orientación psicoanalítica utilizan en sus consultorios, esto es, las técnicas proyectivas, la asociación libre y, en ocasiones, aunque con muchos reparos, la hipnosis.

Según sus partidarios, este tipo de investigación arroja resultados que le dan direccionalidad a las estrategias de mercadotecnia acordes con los verdaderos anhelos profundos del consumidor; dichas estrategias incluyen aspectos como el diseño del producto, su fabricación, la fijación de su precio, su distribución, su promoción y gestión de ventas y, sobre todo, su publicidad que debe buscar la asociación entre las características simbólicas del producto y los anhelos profundos del consumidor.

Cuando esto se logra, se produce la ego-implicación (del inglés ego-involvement, traducido por algunos como "involucramiento"), noción propuesta por Sheriff y Cantrill en 1947 para referirse a aquel estado interno en el que queda una persona cuando un estimulo ambiental logra tocar sus fibras internas más sensibles. Cuando esto ocurre, el individuo se siente irresistiblemente implicado y por lo tanto no puede ser indiferente, se involucra, se emociona y reacciona.

De esta manera, cuando los investigadores descubrieron, por ejemplo, que el anhelo profundo más significativo en el caso de las mujeres era reafirmar su femineidad más que su atractivo ante los hombres, comenzaron a sugerir que los anuncios mostraran mujeres solas admirándose ante el espejo en vez de ser admiradas por un hombre con expresión romántica. Esto ponía el énfasis 
en el aspecto narcisista y era una respuesta a la creciente tendencia a lograr independencia y autonomía por parte de las mujeres.

Las investigaciones sobre los motivos inconscientes también podrían haber resultado útiles para evitar que los mercadólogos cometieran errores al apoyarse en estrategias persuasivas que en un nivel consciente aparentaban funcionar muy bien, pero que al tener nexos inconscientes demasiado conflictivos, significarian a la larga una baja aceptación del producto; tal es el caso de otro ejemplo citado por Packard en el que nos cuenta que en cierta ocasión una agencia había desarrollado la idea, en principio atractiva, de mostrar a madre e hija luciendo un mismo peinado acompañado del texto "doble éxito con papá”. Cuando exploraron superficialmente las repercusiones de esta idea no encontraron mayores reparos, pero cuando indagaron más profundamente mediante entrevistas diseñadas para tal fin, encontraron que la idea activaba hondos resentimientos que resultaban inconvenientes para los anunciantes (Packard, 1973).

Autores más contemporáneos como Rolando Arellano, citan ejemplos análogos que enfatizarian el valor de este tipo de investigaciones para solucionar problemas típicos de la comercialización de productos y servicios. Un ejemplo típico es el de las tortas o ponqués instantáneos que, según Arellano, enfrentan actualmente en América Latina el mismo inconveniente que tuvieron en estados Unidos 25 años atrás. En Estados Unidos, estos ponqués, que sólo requerían la adición de agua y la puesta en el horno para ser preparados en el hogar, fueron lanzados esperando una respuesta muy favorable debido a la economia en tiempo, esfuerzo y dinero que representaban; no obstante, las ventas no reflejaron mayor entusiasmo por parte de las amas de casa norteamericanas.

Nuevamente, al intentar averiguar el porqué de la baja aceptación no se hallaban respuestas satisfactorias debido a que los ponqués eran juzgados como buenos en sabor, precio, facilidad de preparación, confianza en la marca, etc. Cuando se emplearon técnicas más profundas se puso de presente que las mujeres sentían una especie de culpa al presentarle a la familia un alimento que se preparaba fácilmente cuando la idea más primitiva asociada a él era la de la figura de la madre o la abuela sacrificadas que abnegadamente empleaban muchas horas preparando un alimento según recetas y procedimientos tradicionales, lo que evidenciaba el buen cumplimiento de sus deberes de madres que cuidan bien de su familia y demuestran todo el amor y la ternura que se espera de ellas. En la simbología psicoanalitica, el hacer un ponqué está asociado con ser madre por cuanto la masa crece en horno tal cual lo hace el bebé en el seno materno (Arellano, 2002).

La solución propuesta por los investigadores consistió en complicar un poco el procedimiento dejando que las amas de casa agregaran la leche y los huevos y efectuaran una parte de la mezcla. Debe aclararse que la leche y los huevos son elementos considerados como de alto contenido simbólico maternal y sexual en la concepción psicoanalítica.

El resultado, según Arellano, fue un producto con mucho éxito comercial. Este éxito sería el resultado de armonizar las características del producto con los motivos más profundos en la psiquis de las consumidoras. Arellano agrega que las dificultades iniciales del producto tuvieron que ver con el contexto cultural propio de la época en que ocurrió, de tal manera que si el lanzamiento hubiera ocurrido en E.E.U.U en nuestros dias, el producto no hubiera tenido tantos inconvenientes debido a la mayor independencia de las mujeres norteamericanas con respecto a los valores tradicionales.

Pero la independencia y empoderamiento de la mujer no es el único cambio significativo en las tendencias de consumo en la sociedad actual. Los cambios en la dinámica familiar que se vienen presentando en los últimos años han sido cuidadosamente estudiados y seguidos por los profesionales del marketing debido a que afectan directamente los hábitos de compra y consumo de productos y servicios.

Hechos relativamente desconocidos en épocas pretéritas y que hoy son frecuentes, como el de la transformación de la familia nuclear que implican circunstancias como las de personas que viven y consumen solas, o como el de familias que sólo cuentan con uno de los padres, o el de las parejas de homosexuales, y muchos otros casos semejantes, traen cambios en la dinámica intrapsiquica de las personas que deben ser detectados por los expertos en mercadotecnia con el fin de adaptar inmediatamente los productos y servicios y las estrategias de comercialización, que incluyen a la publicidad, si se quiere seguir siendo competitivo en el mercado contemporáneo. 
Por supuesto todas las configuraciones afectivas que se descubren detrás de la preferencia o rechazo por uno $u$ otro producto, servicio o marca han existido siempre, y lo que detectan los estudios es un incremento en su importancia en un mayor número de sujetos. La respuesta en términos de marketing es la oferta y promoción de productos que cumplen el propósito de satisfacer las correspondientes carencias y aspiraciones latentes.

\subsection{Aspectos éticos del erotismo en la publicidad}

En su capítulo sobre los aspectos éticos de la publicidad, William Wells y sus colaboradores John Burnet y Sandra Moriarty (2007), no dudan en incluir el tema sexual entre los más controversiales dentro de la polémica que siempre ha acompañado a la práctica publicitaria. Los demás temas de esta categoría son la tendencia de la publicidad a recurrir a la exageración, el problema del mal gusto, la recurrencia de los estereotipos, las estrategias de la publicidad para niños, la publicidad de productos controversiales y, por supuesto, la publicidad subliminal.

Como en todos los dilemas éticos, el primer punto consiste en establecer los limites permisibles entre lo legal y lo ético, pues resulta obvio que no todo lo permitido por la ley es correcto. Lo anterior es mucho más controversial en el caso de la publicidad en la que la apuesta persuasiva que se pone en juego involucra a todo tipo de espectadores, incluyendo a los niños.

Toda persona tiene ideas propias sobre lo que puede considerarse inmoral, exagerado, de mal gusto, ofensivo o perjudicial para los niños. Esta afirmación no se refiere sólo a los consumidores sino a los publicistas; pero siendo la publicidad un hecho social y cultural, la polémica no puede zanjarse argumentando únicamente desde la perspectiva de los derechos individuales, ya sean éstos los de expresión o los de respeto por la dignidad personal y el libre desarrollo de la personalidad.

De una parte es conveniente tener en cuenta que es el consumidor quien en últimas decide qué es lo que es aceptable o no para él. También es importante reiterar que los profesionales del marketing saben muy bien que muchos consumidores hacen sus elecciones comparando los productos partiendo de criterios éticos, hecho que los obliga a respetar ciertos limites. Pero también es relevante considerar que dichos profesionales siempre han sabido que traspasar los limites es un recurso efectivo para llamar la atención e incluso para lograr la aceptación de algunos consumidores, especialmente los jóvenes (Wells, Burnet, \& Moriarty, 2007).

Debido a la anterior paradoja, también los estudios con pretensiones de rigor científico muestran ambigüedad sobre estos temas. En efecto, con respecto al derecho de recurrir a la exageración, a veces humorística, de los beneficios de un producto que podrian defender algunos publicistas y que los críticos podrian calificar como una forma de engaño, las investigaciones serias presentan resultados que apoyan ambas posiciones. En algunos estudios se ha evidenciado que los consumidores suelen hacer inferencias que van más allá del contenido manifiesto del anuncio, interpretando lo prometido en un sentido fantasioso, otorgando un alto grado de credibilidad, tal vez ingenua, a la capacidad del anunciante de cumplir su promesa. Sin embargo, otros estudios encontraron que la inclusión de afirmaciones exageradas no modificaba la respuesta de los consumidores. Algo similar se encontró con respecto a la recordación de dichos anuncios y en cuanto a la credibilidad concedida.

E1 rechazo moralista, que muchas veces se disfraza de rechazo estético pues se habla de "mal gusto", suele encontrarse en los anuncios de productos como las toallas higiénicas, la ropa interior y los licores. Este rechazo es común en las personas que sienten vergüenza de que se traten abiertamente ciertos temas. Es un hecho que los criterios morales cambian con la época. Hoy en día nos sorprende la reacción que produjo un anuncio de un desodorante que provocó la cancelación inmediata de la suscripción al diario en el que apareció. El escándalo lo suscitó el siguiente texto: "¿Es usted una de las muchas mujeres que tienen problemas con la transpiración excesiva?" (Wells et al., 2007).

Aunque el empleo de los estímulos eróticos en la publicidad no es nada nuevo, la polémica no parece acabar por cuanto los anunciantes van cada vez más lejos en su propósito de no pasar desapercibidos. Muchos profesionales del marketing no tienen inconvenientes en explicar su proceder en función de su obligación de atraer la atención de las nuevas generaciones: 


\begin{abstract}
Quizás es una nueva tendencia. Creo que la gente está haciendo un gran esfuerzo por encontrar nuevas formas de hablarle al auditorio. Si la gente no obtiene lo que espera haciendo las cosas en la forma tradicional, buscará formas nuevas e interesantes para hacer que las cosas sucedan.
\end{abstract}

Otro profesional del medio afirmó: "Lo que esto hace es obligar a tipos como yo a tratar de pensar en métodos alternativos para que [el mercado de la moda y los cosméticos] cobre importancia".

Los críticos responderian que lo que se está intentando no es nuevo ni interesante sino que se está cayendo en el facilismo de apelar a los más bajos impulsos de la naturaleza humana. Lo que no es discutible es que la estrategia parece funcionar como lo demuestra su utilización permanente.

En una revisión de las diferentes posturas sobre este tema no puede faltar la de los defensores de la libertad de expresión y del derecho a la exhibición de todas las facetas de la naturaleza humana, incluyendo a las que muchos calificarian como vulgares o inmorales. Veamos un ejemplo de tales argumentos: "La negación de la naturaleza humana no deja sino hipocresías, moralismo fariseo y una colosal ridiculez" (Abad Faciolince, 2010). Desde este punto de vista, se argumenta que nadie tiene derecho a imponer a los demás sus concepciones morales ni sus principios religiosos. Se afirma que una cosa es que alguien crea que alguna conducta es pecaminosa, y que por lo tanto restrinja su propio comportamiento en tal sentido, y otra cosa que se decrete que tal conducta es delictiva con la intención de restringir las libertades ajenas. Visto así, estariamos ante una abusiva e ilegal coartación del derecho al libre desarrollo de la personalidad. No puede ignorarse que la investigación antropológica ha demostrado hasta la saciedad que diferentes sociedades y culturas desarrollan diferentes patrones culturales y que, por lo tanto, lo que es legal, normal y aceptable en una cultura no lo es en otra; lo anterior hace que cualquier concepto de moralidad o inmoralidad, o, si se quiere, de normalidad o anormalidad, sea relativo al contexto cultural en el que es puesto en juego (Mann, 1973).
En los tiempos actuales, con el auge del intercambio cultural ocasionado por los grandes avances en los medios de comunicación, el individuo corriente ya no está expuesto solamente a la escala de valores de su familia y su círculo personal, sino a todas las manifestaciones culturales que existen en el planeta. Esto hace que la persona no solamente tenga que elegir entre aceptar o rechazar los valores en los que es educado en primera instancia, sino que tiene que elegir entre todos los sistemas de valores que compiten por persuadirlo.

El ascenso del sujeto, otra característica de la vida en los tiempos actuales, hace que desde muy joven la persona reclame y ejerza, cada vez con menos restricciones, el derecho a elegir por sí mismo lo que le concierne, limitando las aspiraciones con respecto a lo que debería ser su estilo de vida de parte del colectivo en el que vive, incluyendo a los padres, los educadores, los medios de comunicación y el mismo Estado.

La persona corriente no sólo tiene fácil acceso a toda la información que desee consultar, sino que puede emitir su verdad ante quien esté interesado; y con igual facilidad puede intentar difundir su propia cosmovisión y su propia escala de valores. En ocasiones ya no se trata de debatir si se debería prohibir alguna conducta sino de si es posible hacerlo.

\section{Hipótesis}

Para la ejecución del presente proyecto fueron formuladas 31 hipótesis afirmando que los estímulos eróticos, los símbolos inconscientes y los contenidos subliminales sí tendrian influencia persuasiva sobre los sujetos tanto en su preferencia por el anuncio, como en la disposición de compra. También se formularon hipótesis sobre la manifestación del rechazo moralista, del reconocimiento de la estrategia utilizada y las diferencias en las respuestas entre los sujetos de uno u otro sexo.

\footnotetext{
"La metodologia y el desarrollo de esta investigación se presentará en el siguiente número de la revista
} Panorama." 


\section{Agradecimientos}

A todos los estudiantes universitarios que colaboraron como sujetos de investigación.

Al Doctor Christian Schrader Valencia, Decano del Programa de Publicidad de la Universidad Jorge Tadeo Lozano por su constante apoyo y buenos oficios para adelantar exitosamente este proyecto.

A los profesores Andrés Rodríguez Martínez, José Castillo y Carlos Santacruz por su trabajo en la planeación y realización de las piezas publicitarias necesarias para adelantar el presente proyecto.

A los estudiantes semilleros y asistentes que participaron en todas las fases de desarrollo de este proyecto.

El arte de la persuasión es el eje fundamental de las relaciones humanas propias de la convivencia civilizada, en contraposición a la intimidación y el uso de la fuerza, propias de la barbarie.

\section{Referencias}

1. Abad Faciolince, H. (20 de Febrero de 2010). Pedradas al hombre adúltero. El Espectador

2. Arellano, R. (2002). Comportamiento del consumidor. Enfoque América Latina. México: McGraw-Hill.

3. Balle, F. (1991). Comunicación y sociedad. Bogotá: Tercer Mundo.

4. Brenner, C. (1964). Elementos fundamentals de psicoanálisis. Libros Básicos.

5. Byerly, H. (1976). Explaining and exploiting placebo effects. Perspectives in biology and medicine , número 19, 423-236.

6. Campbell, D. \& Stanley, J. (1970). Diseños experimentales y cuasiexperimentales en la investigación social. Buenos Aires: Amorrortu.

7. Dethlefsen, T. \& Dahlke, R. (1998). La enfermedad como camino. Barcelona: Plaza \& Janes.

8. Feldman, R. (1998). Psicología. México: McGraw-Hill.

9. Freud, S. ([1916] 1948). Introducción al psicoanálisis. En S. Freud, Obras Completas (Vol. II). Madrid: Biblioteca Nueva.

10. Garrison, M. \& Loredo, O. (2002). Psicología. México: McGraw-Hill.

11. Inglis, B. (1995). Trance. Historia de los estados especiales de la mente. Girona: Susaeta.

12. Jung, C. \& Wilhelm, R. (1974). El secreto de la flor de oro. Buenos Aires: Paidós.

13. Key, W. (1987). Seducción subliminal. México: Diana.

14. Loudon, D. \& Della Bitta, A. (1995). Comportamiento del consumidor. México: McGraw-Hill.

15. Mann, L. (1973). Elementos de psicología social. México: Limusa.

16. Mastrodoménico, H. (1979). Psicología deportiva: el efecto placebo sobre el rendimiento en un ejercicio de resistencia aeróbica. Tesis de Grado. Bogotá: Universidad Nacional de Colombia.

17. Morris, C. (1987). Psicología. México: Prentice-Hall.

18. Morris, C. \& Maisto, A. (2001). Introducción a la Psicología. México: Prentice-Hall. 
19. Mucchielli, R. (1977). Psicología de la publicidad y de la propaganda. Bilbao: Mensajero.

20. Packard, V. (1973). Las formas ocultas de la propaganda. Buenos Aires: Sudamericana.

21. Pérez, A. (1978). El efecto placebo en psicoterapia. En A. Pérez, Monografías psicológicas: Psicología clínica. Bogotá: Universidad de los Andes.

22. Piaget, J. (1980). Problemas de psicología genética. Barcelona: Ariel.

23. Shapiro, A. (1971). Placebo effects in medicine, psychotherapy and psychoanalysis. En Borging \& Garfield, Handbook of psychotherapy and behavior change.

24. Wells, W., Burnet, J. \& Moriarty, S. (2007). Publicidad, principios y prácticas. México: Pearson.

25. Wilhelm, R. (1982). I Ching. El libro de las mutaciones. Barcelona: Edhasa. 